\title{
Chemical and biological conversion of crude glycerol derived from waste cooking oil to biodiesel
}

\author{
Jiaxin Chen ${ }^{\mathrm{a}, \mathrm{b}}$, Song Yan ${ }^{\mathrm{b}}$, Xiaolei Zhang ${ }^{\mathrm{a}, *}$, Rajeshwar Dayal Tyagi ${ }^{\mathrm{b}}$, Rao Y. Surampalli ${ }^{\mathrm{c}}$, J.R. Valéro ${ }^{\mathrm{b}}$ \\ ${ }^{a}$ School of Civil and Environmental Engineering, Harbin Institute of Technology (Shenzhen), Shenzhen, Guangdong 518055, PR China \\ ${ }^{\mathrm{b}}$ INRS Eau, Terre et Environnement, 490, rue de la Couronne, Québec G1K 9A9, Canada \\ ' Department of Civil Engineering, University of Nebraska-Lincoln, N104 SEC, PO Box 886105, Lincoln, NE 68588-6105, USA
}

\section{A R T I C L E I N F O}

\section{Article history:}

Received 16 May 2017

Revised 24 October 2017

Accepted 25 October 2017

Available online $\mathrm{xxxx}$

\section{Keywords:}

Crude glycerol

Energy

Lipid accumulation

Biodiesel

\begin{abstract}
A B S T R A C T
In this study, crude, purified, and pure glycerol were used to cultivate Trichosporon oleaginosus for lipid production which was then used as feedstock of biodiesel production. The purified glycerol was obtained from crude glycerol by removing soap with addition of $\mathrm{H}_{3} \mathrm{PO}_{4}$ which converted soap to free fatty acids and then separated from the solution. The results showed that purified glycerol provided similar performance as pure glycerol in lipid accumulation; however, crude glycerol as carbon source had negatively impacted the lipid production of T. oleaginosus. Purified glycerol was later used to determine the optimal glycerol concentration for lipid production. The highest lipid yield $0.19 \mathrm{~g} / \mathrm{g}$ glycerol was obtained at $50 \mathrm{~g} /$ $\mathrm{L}$ purified glycerol in which the biomass concentration and lipid content were $10.75 \mathrm{~g} / \mathrm{L}$ and $47 \% \mathrm{w} / \mathrm{w}$, respectively. An energy gain of $4150.51 \mathrm{MJ}$ could be obtained with 1 tonne of the crude glycerol employed for biodiesel production through the process proposed in this study. The biodiesel production cost estimated was 6.32 US \$/gal. Fatty acid profiles revealed that $C 16: 0$ and $C 18: 1$ were the major compounds of the biodiesel from the lipid produced by T. oleaginosus cultivated with crude and purified glycerol. The study found that purified glycerol was promising carbon source for biodiesel production.
\end{abstract}

(c) 2017 Published by Elsevier Ltd.

\section{Introduction}

One of the most urgent issues in the world is to seek renewable, sustainable, and affordable energy source due to the risk of the depletion of petro energy. Biodiesel is gaining increasing attention as it can be produced by renewable and cheap materials. The dramatic increase in demand of biodiesel resulted in its increased production from various types of oils. The common method of biodiesel production is trans-esterification in which oils or fats react with short chain alcohol (generally methanol) with acid or base as catalyst. In the process, crude glycerol is generated as by-product. About $0.10 \mathrm{~kg}$ of glycerol is generated per kilogram of biodiesel produced. It is normally called crude glycerol and mainly contains glycerol (20-96\% w/w), free fatty acids, soaps, catalyst, salts, methanol etc. (Gao et al., 2016; Hansen et al., 2009; Hu et al., 2012). The composition of crude glycerol varies from one biodiesel production plant to another and is mainly determined by the feedstock oil composition and quality, the oil and methanol molar ratio used in transesterification, type of catalyst used, and the detailed procedure

\footnotetext{
* Corresponding author.

E-mail address: xiaolei.zhang2016@foxmail.com (X. Zhang).
}

such as with or without methanol recovery (Athalye et al., 2009; Uprety et al., 2017; Yen et al., 2012).

Crude glycerol is a complex material, and the proper utilization to attain its maximum value is desirable for its appropriate handling. Purification of crude glycerol was the most applied method before biodiesel boom. However, due to a substantial decrease in the price of purified glycerol (1.54 US $\$ / \mathrm{kg}$ before 2000 and 0.66 US $\$ / \mathrm{kg}$ after 2007), the purification is getting less attractive. Therefore, direct use or partial purification of crude glycerol is becoming promising. Due to the large demand on energy in the current world, use of crude glycerol for energy production has been widely reported (Nartker et al., 2014; Oliveira et al., 2015; Trchounian et al., 2016). Bioconversion of glycerol to biodiesel is an interesting way of utilization of original or partially purified crude glycerol. Oleaginous microorganisms such as Schizochytrium sp., Yarrowia lipolytica, Rhodotorula sp., and Cryptococcus sp. are reported capable of assimilating glycerol to produce lipid which is the raw material of biodiesel production (Deeba et al., 2016; Gao et al., 2016; Polburee et al., 2015; Ryu et al., 2013).

Current studies revealed that the composition of crude glycerol had great impact on lipid accumulation in microorganisms (Cerón-García et al., 2013; Polburee et al., 2015). Normally, high 
glycerol content in crude glycerol tends to lead high lipid accumulation in microorganism. Study showed that the lipid accumulation reached around $60 \% \mathrm{w} / \mathrm{w}$ (lipid $\mathrm{g} /$ biomass $\mathrm{g}$ ) with pure glycerol as carbon source, which was only $20 \% \mathrm{w} / \mathrm{w}$ (lipid $\mathrm{g}$ / biomass g) when crude glycerol was applied as carbon source (Polburee et al., 2015). The highest biomass and lipid concentration reached $26.7 \mathrm{~g} / \mathrm{L}$ and $18.5 \mathrm{~g} / \mathrm{L}$ when utilized crude glycerol with $85 \%$ glycerol content, respectively, but they were $18.0 \mathrm{~g} / \mathrm{L}$ and $13.4 \mathrm{~g} / \mathrm{L}$ when the crude glycerol with glycerol content of $33 \%$, respectively (Xu et al., 2012).The content of impurities including methanol and soap have showed significant effect on cell growth as well as lipid accumulation (Liang et al., 2010a; Lorenz et al., 2017). It was revealed that biomass productivity of Cryptococcus curvatus cultivated with crude glycerol medium was only $67 \%$ of that from pure glycerol with the same carbon concentration (Liang et al., 2010a). Lipid accumulation in Kodamaea ohmeri with crude glycerol was only $50 \%$ of that with pure glycerol (Kitcha and Cheirsilp, 2011). Gao et al. (2016) found that the lipid productivity of Rhodosporidium toruloides in crude glycerol cultivation was reduced around $18 \%$ compared with that of pure glycerol cultivation (Gao et al., 2016). Overall, crude glycerol with high glycerol content and low impurity content showed advantage on lipid production from oleaginous microorganism.

Crude glycerol composition is highly related to the character of feedstock oil of biodiesel production. The crude glycerol with high glycerol content $(>60 \%)$ was normally generated in the biodiesel production from plant seed oils which have low free fatty acid (FFA) content. It suggests that FFA content in the feedstock oil has great impact on the final glycerol content in crude glycerol as FFA can be transferred to soap during the transesterification in base catalyzed reaction. As the prices of plant seed oils are increasing, waste cooking oils which have high FFA content are largely employed in biodiesel production, and hence the production of crude glycerol with high soap content is gradually increasing. In order to reduce the influence on lipid production from microorganism, soap can be removed from crude glycerol prior to the utilization. By soap removal, the glycerol content will be increased in the crude glycerol, and thus the purified crude glycerol could enhance the production of biomass and lipid from oleaginous microorganisms. In addition, it would bring extra value to the process if the recovered soap could be also converted to useful product. In fact, soap in crude glycerol can be converted to FFA which can be used to produce biodiesel with acid as catalyst.

In this study, crude glycerol generated in the biodiesel production from waste cooking oil, which has low glycerol content, was used as carbon source for oleaginous yeast cultivation after FFA recovery. The obtained FFA from crude glycerol purification was then transferred to biodiesel through esterification. The study provides a way to maximize the value of crude glycerol with low glycerol content. In addition, the work increases energy efficiency as energy (biodiesel) production by-product (crude glycerol) again converted to energy (biodiesel). It provides a feasible method to manage crude glycerol and create energy. The flow diagram of the study is shown in Fig. 1.

\section{Materials and methods}

\subsection{Materials}

Crude glycerol was kindly provided by a biodiesel production plant, in Quebec, Canada. Oleaginous microorganism Trichosporon oleaginosus (ATCC20509) was employed in this study to produce lipid.

\subsection{Crude glycerol characterization}

Density and $\mathrm{pH}$ : The weight of $2 \mathrm{~mL}$ of crude glycerol was measured at room temperature. The density of crude glycerol was determined by dividing the weight with the volume $(2 \mathrm{~mL})$.To determine the $\mathrm{pH}, 1.0 \mathrm{~g}$ of crude glycerol was dissolved in $50 \mathrm{~mL}$ of deionized (DI) water. The $\mathrm{pH}$ of the solution was measured by a digital $\mathrm{pH}$ meter at room temperature (Hu et al., 2012).

Glycerol content: The glycerol content was determined according to the method reported by Bondioli and Della Bella (2005). 3,5diacetyl-1,4-dihydrolutidine, a yellow complex, was formed in a two-step reaction. In the first step, glycerol reacted with sodium periodate to form formaldehyde, following, acetyl acetone was added to generate the complex of 3,5-diacetyl-1,4-dihydrolutidine. The complex was measured by UV-Vis Spectrophotometer at $410 \mathrm{~nm}$. The glycerol content was calculated according to standard curve $\left(=0.05645 \times\right.$ conc $\left.-0.07437 ; \mathrm{R}^{2}=0.99534\right)$. The method is a well established one for glycerol determination (Lima et al., 2012; Sidnei et al., 2011). It could rapidly and accurately determine glycerol concentration in liquid. To verify the method, glycerol was also determined with High Performance Liquid Chromatography (HPLC), and results showed that Bondioli and Bella method was reliable. Thus, Bondioli and Bella method was used in this study to determine glycerol concentration.

Soap content: The soap content was estimated as reported by Liang and co-workers (Liang et al. (2010b). The $\mathrm{pH}$ of $50 \mathrm{~g}$ crude glycerol was adjusted to 1.0 with $85 \% \mathrm{H}_{3} \mathrm{PO}_{4}$. After well mixing, the solution was centrifuged at $5000 \mathrm{rpm}$ for $20 \mathrm{~min}$. The top red dark layer (in the centrifuged liquid) which was FFA was collected and weighed. The soap content was calculated according to soap amount $=304 \times$ FFA amount $/ 282$; where 304 is average soap molar mass and 282 is the average FFA molar mass.

Biodiesel content: Biodiesel content was analyzed with Gas Chromatography coupled with Mass Spectroscopy (GC-MS) (Perkin Elmer, Clarus 500) to control the result quality. Helium was used as the carrier gas. The dimensions of the column used were $30 \mathrm{~m} \times 0.25 \mathrm{~mm}$, with a phase thickness of $0.2 \mu \mathrm{m}$. The calibration curve was prepared by injecting known concentrations of an external standard, mixture comprising 37 FAMEs (47885-U, 37 Component FAME Mix; Supelco, Bellefonte, PA, USA). 1,3-dichlorobenzene was also used as internal standard with a concentration of $50 \mathrm{ppm}$.

Ash content: The $10 \mathrm{~g}$ of crude glycerol was heated at $750^{\circ} \mathrm{C}$ for $3 \mathrm{~h}$ (Manosak et al., 2011). After the sample was cooled down to room temperature, the residue $\left(\mathrm{W}_{3}\right)$ was weighed and then the ash content was calculated $\left(\mathrm{W}_{3} / 10 \times 100 \%\right)$.

Catalyst content: Crude glycerol was sampled from a company in which $\mathrm{NaOH}$ was used as the catalyst in the transesterification process to produce the biodiesel. To determine the content of $\mathrm{NaOH}, 10 \mathrm{~g}$ of crude glycerol was adjusted to $\mathrm{pH} 7$ with $1 \mathrm{M} \mathrm{HCl}$ and the consumed volume of acid $1 \mathrm{M} \mathrm{HCl}(\mathrm{V})$ was recorded and used to calculate the $\mathrm{NaOH}$ content $(=40 \times 1 \times \mathrm{V} / 10$; where 40 is $\mathrm{NaOH}$ molar mass, 1 is $\mathrm{HCl}$ molar concentration, $\mathrm{V}$ is the volume of $1 \mathrm{M} \mathrm{HCl}$ consumed to bring the $\mathrm{pH}$ to 7 ; and 10 is crude glycerol amount) in crude glycerol.

Methanol content: The methanol content was determined with Heidolph Laborota 4011 digital evaporator. The $100 \mathrm{~mL}$ (107.3 g) of crude glycerol was subjected to $60^{\circ} \mathrm{C}$ for $15 \mathrm{~min}$. The evaporated methanol $\left(\mathrm{W}_{4}\right)$ was collected and the methanol content in the crude glycerol was calculated as follows: $\mathrm{W}_{4} / 107.3 \times 100 \%$.

Water content: The $10 \mathrm{~g}$ of crude glycerol was heated at $105^{\circ} \mathrm{C}$ until weight constant $\left(\mathrm{W}_{5}\right)$. The weight loss during the heating was due to the evaporation of water and methanol. The sum of water and methanol content was calculated as follows: [(10$\left.\left.\mathrm{W}_{5}\right) / 10 \times 100 \%\right]$. After subtracting methanol content, water content was obtained. 


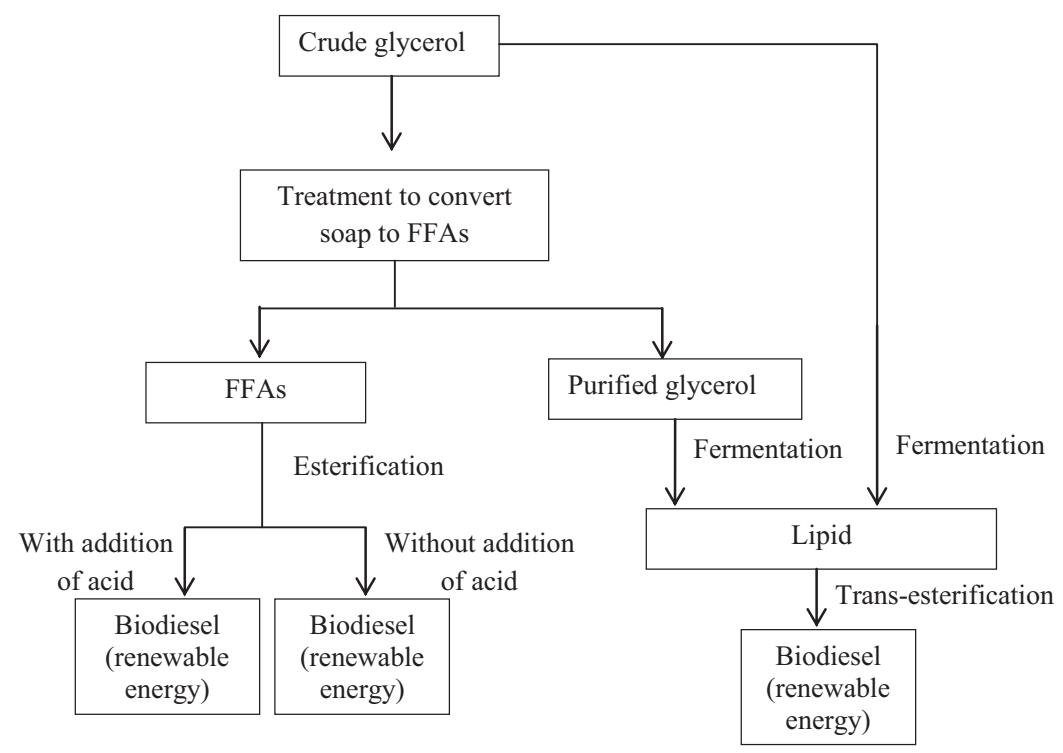

Fig. 1. The flow diagram of the study.

\subsection{Soap conversion to free fatty acid (FFAs)}

According to the information of the catalyst amount added during trans-esterification provided by biodiesel production industry, different volume $(1,2,3,4,5,6,7,8,9$ and $10 \mathrm{~mL})$ of $85 \%$ phosphoric acid was added to $40 \mathrm{~mL}$ of crude glycerol, respectively, to determine the optimal acid addition for converting soap to FFAs. After well mixing, the mixtures were allowed to separate into three layers with the FFA as the top layer, the precipitate (salt) in the middle, and purified glycerol in the bottom. The FFA and purified glycerol were collected and stored, respectively, for further utilization.

\subsection{Lipids production with glycerol}

Crude and purified glycerol (obtained by removing soap) was used as carbon source to cultivate oleaginous microorganism $T$. oleaginosus for lipid production. Prior to utilization, they were sterilized at $121^{\circ} \mathrm{C}$ for $15 \mathrm{~min}$ to remove methanol due to the concern on that methanol could inhibit the growth of T. oleaginosus.

The pre-culture was prepared by inoculating a loopful of $T$. oleaginosus in the sterilized media containing $10 \mathrm{~g} / \mathrm{L}$ yeast extract, $20 \mathrm{~g} / \mathrm{L}$ peptone, and $20 \mathrm{~g} / \mathrm{L}$ glucose. After $24 \mathrm{~h}$ incubation, the preculture was transferred to the sterilized fermentation medium containing (per liter): $2.7 \mathrm{KH}_{2} \mathrm{PO}_{4}, 0.95 \mathrm{Na}_{2} \mathrm{HPO}_{4}, 0.404 \mathrm{NH}_{4} \mathrm{Cl}$, $0.2 \mathrm{MgSO}_{4} \cdot 7 \mathrm{H}_{2} \mathrm{O}, 0.1 \mathrm{~g}$ yeast extract, 0.1 EDTA, $0.04 \mathrm{CaCl}_{2} \cdot 2 \mathrm{H}_{2} \mathrm{O}$, $0.0055 \mathrm{FeSO}_{4} \cdot 7 \mathrm{H}_{2} \mathrm{O}, 0.0052$ citric acid $\mathrm{H}_{2} \mathrm{O}, 0.001 \mathrm{ZnSO}_{4} \cdot 7 \mathrm{H}_{2} \mathrm{O}$, and $0.00076 \mathrm{MnSO}_{4} \cdot \mathrm{H}_{2} \mathrm{O}$ and $25 \mathrm{~g}$ crude, purified, or pure (Certified ACS, Fisher Scientific) glycerol (Meesters et al., 1996; Zheng et al., 2012). The pH of the medium was adjusted to 6.5 and then sterilized at $121^{\circ} \mathrm{C}$ for $15 \mathrm{~min}$ prior to inoculation. The fermentation was performed in shake flasks under aerobic conditions. The incubation was performed at $28^{\circ} \mathrm{C}$ with $170 \mathrm{rpm}$.

To study glycerol concentration effect on lipid accumulation of T. oleaginosus, the purified glycerol was used and the investigated concentration was $25,50,75$, and $100 \mathrm{~g} / \mathrm{L}$. The fermentation was conducted similarly as that with different type of glycerol (crude, purified, and pure).The maximum lipid accumulation of $T$. oleaginosus normally was at $48-96 \mathrm{~h}$, thus the fermentation was conducted for $120 \mathrm{~h}$ (Gong et al., 2016; Seo et al., 2013).

\subsection{Residual glycerol analysis}

The residual glycerol after fermentation was analyzed with Bondioli and Bella method as described above.

\subsection{Lipid extraction from yeast biomass}

The standard chloroform and methanol extraction procedure with minor modification was employed to determine the lipid content in the biomass (Folch et al., 1957; Vicente et al., 2009). Biomass was harvested from the fermented broth by centrifugation at $5000 \mathrm{rpm}$ for $15 \mathrm{~min}$ followed by 2 times washing with distilled water, and then dried by lyophilisation. The extraction was performed as following: the $\mathrm{M}$ (around 200) $\mathrm{mg}$ lyophilized biomass was mixed with $4 \mathrm{~mL}$ solvent containing chloroform and methanol $(2: 1 \mathrm{v} / \mathrm{v})$; the solution was subjected to $60^{\circ} \mathrm{C}$ for $4 \mathrm{~h}$; the mixture was then centrifuged at $5000 \mathrm{rpm}$ for $15 \mathrm{~min}$ and the supernatant (solvent phase) was withdrawn and transferred into a pre-weighed glass vial $\left(\mathrm{W}_{6}\right)$; the procedure was repeated for the second time extraction, and the supernatant was transferred to the same vial (the pre-weighed glass vial). The vial containing the supernatant obtained from the two extractions was put in the oven set at temperature of $60^{\circ} \mathrm{C}$ to evaporate the solvents. It was considered that the evaporation was complete when the weight of the vial stopped changing, and the weight $\left(\mathrm{W}_{7}\right)$ was noted down. The lipid amount was calculated by the difference of $W_{6}$ and $W_{7}$. The lipid content in the biomass of $T$. oleaginosus was calculated as: $\left(W_{7}-W_{6}\right) /$ $M \times 100 \%$, where $M$ was the biomass amount used in the extraction (around $200 \mathrm{mg}$ in this study). The obtained lipid was then converted to biodiesel through trans-esterification.

\subsection{Free fatty acid content in lipids extracted from biomass}

The FFA content was determined with titration method (Woyewoda et al., 1976). Samples collected at $48 \mathrm{~h}$ fermentation were used to determine FFA content in lipids. The lipid was extracted as described before on Section 2.6. The extracted lipids was dissolved in $5 \mathrm{~mL}$ hexane and transferred to a $100 \mathrm{~mL}$ conical flask. Hexane was then evaporated at $60^{\circ} \mathrm{C}$. The $10 \mathrm{~mL}$ of chloroform: methanol $2: 1 \mathrm{v} / \mathrm{v}$ mixture was added to the conicals flask with and without (blank) lipids, respectively, and then two drops 
of phenolphthalein was added, respectively as well. The $0.01 \mathrm{~N}$ $\mathrm{KOH}$ filled in $25 \mathrm{~mL}$ burette was added to the conical flasks drop by drop with gentle agitation. The titration was ended when a pink colour was observed and persisted at least for $5 \mathrm{~s}$. The volume of $\mathrm{KOH}$ used was recorded to calculate the FFA content using Eq. (1).

FFA content as oleic acid $(\%)=28.2 \times \mathrm{N} \times(\mathrm{V}-\mathrm{B}) / \mathrm{W}_{\text {lipid }}$

$$
\times 100 \%
$$

where $\mathrm{V}=$ the volume $(\mathrm{mL})$ of titration solution; $\mathrm{B}=$ the volume $(\mathrm{mL})$ of the blank; $\mathrm{N}=$ the normality of the titration solution $(\mathrm{KOH}) ; \mathrm{W}_{\text {lipid }}=$ the weight of the oil sample (grams).

\subsection{Esterification of FFAs and trans-esterification of lipids}

The FFA obtained from soap (as described above) were converted to fatty acids methyl esters (FAMEs, biodiesel) by reacting with methanol in the absence or presence of acid. The $5 \mathrm{~mL}$ of acidic (sulfuric acid $2 \% \mathrm{v} / \mathrm{v}$ in methanol) methanol was added to $0.2 \mathrm{~g}$ of FFA. The mixture was then heated to $50{ }^{\circ} \mathrm{C}$ for $24 \mathrm{~h}$. The 1,3-dichlorobenzene was used as internal standard. After reaction $(24 \mathrm{~h})$, the $5 \% \mathrm{NaCl}$ solution was added ( $100 \mathrm{~mL}$ per gram of lipids), and then FAMEs was extracted by washing two times with hexane (100 mL per gram of lipid), and the upper hexane layer was recovered by phase separation. The FAMEs in hexane was washed with $2 \%$ sodium bicarbonate $(20 \mathrm{~mL}$ per gram lipid), and the top layer was dried in oven at $60{ }^{\circ} \mathrm{C}$ (Halim et al., 2011).

The lipids obtained by solvent extraction from $T$. oleaginosus in vials was first dissolved in hexane $(5 \mathrm{~mL})$; then mixed with methanol. Lipid to methanol molar ratio was $1: 6(0.3 \mathrm{~mL}$ methanol for per gram lipid). Sodium hydroxide $(0.5 \% \mathrm{w} / \mathrm{w}$ oil $)$ was used as catalyst. The mixture was then subjected to $55^{\circ} \mathrm{C}$ in oil bath for $2 \mathrm{~h}$. The 1,3-dichlorobenzene was used as internal standard with a concentration of $50 \mathrm{ppm}$. The procedure of FAMEs recovery was similar as that of FAMEs converted from FFA.

The FAMEs in hexane were analyzed using a Gas Chromatography coupled with Mass Spectroscopy (GC-MS) (Perkin Elmer, Clarus 500) as described above for biodiesel content determination.

All the experiments were performed in triplicate and average results were reported with standard deviation less than $5 \%$.

\section{Results and discussion}

\subsection{Crude glycerol composition}

The composition of crude glycerol was determined and the results were given in Table 1 . It was observed that the crude glycerol has low glycerol content $(31.8 \pm 0.3 \% \mathrm{w} / \mathrm{w})$ and high soap content $(21.1 \pm 0.3 \% \mathrm{w} / \mathrm{w})$. It would be due to the high content of FFA in the feedstock of the alkaline catalytic biodiesel production. Soap could be an inhibitor of cell growth as it can attach on cells and

Table 1

Composition of crude glycerol and purified glycerol.

\begin{tabular}{lll}
\hline Items & Crude glycerol & Purified glycerol \\
\hline Glycerol content $(\% \mathrm{w} / \mathrm{w})$ & $31.8 \pm 0.3$ & $55.0 \pm 0.2$ \\
Soap content $(\% \mathrm{w} / \mathrm{w})$ & $21.1 \pm 0.3$ & 0.0 \\
Catalyst content $(\mathrm{NaOH})(\% \mathrm{w} / \mathrm{w})$ & $2.8 \pm 0.2$ & 0.0 \\
Biodiesel content $(\% \mathrm{w} / \mathrm{w})$ & $1.2 \pm 0.0$ & $1.5 \pm 0.0$ \\
Ash $(\% \mathrm{w} / \mathrm{w})$ & $2.3 \pm 0.1$ & $4.2 \pm 0.2$ \\
Methanol $(\% \mathrm{w} / \mathrm{w})$ & $15.3 \pm 0.3$ & $18.5 \pm 0.6$ \\
Water $(\% \mathrm{w} / \mathrm{w})$ & $24.4 \pm 0.2$ & $20.8 \pm 0.8$ \\
pH & $8.93 \pm 0.04$ & $3.93 \pm 0.25$ \\
Density $(\mathrm{g} / \mathrm{mL})$ & $1.073 \pm 0.06$ & $1.101 \pm 0.03$ \\
\hline
\end{tabular}

interfere to the nutrient transportation from fermentation medium to cell bodies. Therefore, soap removal was performed.

\subsection{Free fatty acid recovery from soap}

The high soap content in crude glycerol (Table 1 ) is due to presence of high concentration of FFA in the feedstock oil. In alkaline condition $(\mathrm{pH}>7)$, FFAs react with base $(\mathrm{NaOH}$ or $\mathrm{KOH})$ to form soap (the equilibrium of the reaction of Eq. (2) is shifted to right). On the contrary, FFA will be released due to the dissociation of soap (the equilibrium of the reaction of Eq. (2) is shifted to left) at low $\mathrm{pH}$ (FFA recovery process by lowering $\mathrm{pH}$ of the crude glycerol).

$\mathrm{R}_{\mathrm{X}}-\mathrm{COOH}+\mathrm{NaOH} / \mathrm{KOH} \leftrightarrow \mathrm{R}_{\mathrm{X}}-\mathrm{COONa} / \mathrm{K}$

where $R_{X}$ presented $C_{n} H_{2 n+1}$ for saturated and $C_{n} H_{(2(n-m)+1)}$ for unsaturated $(m=1,2,3, . . ; n>2 ; n>m)$.

To recover FFA, the $\mathrm{pH}$ of the crude glycerol was lowered to less than 7. It was observed that FFA stood in the top, purified glycerol was in the bottom, and the middle layer was the salt precipitates after $\mathrm{pH}$ adjustment. This observation was different from few other reports in the literature, which obtained the middle layer as glycerol and bottom layer as salt precipitates (Kelly, 2006; Swearingen, 2006). It could be due to the difference of the composition of the crude glycerol, which led to the variation in density of the precipitates. The results of FFAs recovery was shown in Table 2. There was $8.11 \mathrm{~g}$ of FFA in $40 \mathrm{~mL}$ crude glycerol (at $\mathrm{pH} \mathrm{1}$ ). The phase separation of samples 2-10 with addition of $85 \% \mathrm{H}_{3} \mathrm{PO}_{4}$ started after 15 min settling, and completed at around $72 \mathrm{~h}$. With addition of $1 \mathrm{~mL}$ of $85 \% \mathrm{H}_{3} \mathrm{PO}_{4}$ (sample 1), layer separation was not observed until $3 \mathrm{~h}$. The FFA amount obtained from samples 2-10 was almost the same (Table 2), and there was only $1.32 \mathrm{~g}$ FFAs obtained in sample 1. Compared to other samples, sample 2 ( $2 \mathrm{~mL}$ of $85 \% \mathrm{H}_{3} \mathrm{PO}_{4}$ in $40 \mathrm{~mL}$ of crude glycerol) gave comparable FFA recovery efficiency $(99.2 \% \mathrm{w} / \mathrm{w})$ and highest concentration of glycerol $(54.96 \% \mathrm{w} / \mathrm{w}$ ) with shortest settling time (36 h). Therefore, $2 \mathrm{~mL}$ acid addition to $40 \mathrm{~mL}$ crude glycerol was considered the optimal acid requirement for FFA recovery when gravity settling was used for phase separation and thus to recover glycerol from its crude form.

\subsection{Conversion of free fatty acids to biodiesel}

As mentioned, FFA can consume alkaline catalyst to form soap; hence, acid catalyst should be used in the conversion of FFA to biodiesel (FAMEs). In the process of FFA recovery from soap, $\mathrm{H}_{3} \mathrm{PO}_{4}$ was added to lower the $\mathrm{pH}$. It suggested that the recovered FFA contained the acid; therefore, the addition of acid in the esterification could be avoided. To investigate if it is still necessary to add the acid in the reaction to produce biodiesel from FFA, esterifications of FFA with and without $\mathrm{H}_{2} \mathrm{SO}_{4}$ were conducted. The results showed that the FAMEs yield (g FAMEs/g FFAs) was $90.8 \%$ with $\mathrm{H}_{2} \mathrm{SO}_{4}$ and $32.1 \%$ without $\mathrm{H}_{2} \mathrm{SO}_{4}$, respectively.

According to calculations, the $\mathrm{H}^{+}$present in FFA is $0.49 \mathrm{mmol}$ per $0.2 \mathrm{~g}$ FFA. $5 \mathrm{~mL}$ methanol was added to react with $0.2 \mathrm{~g}$ FFA; therefore, the $\mathrm{H}^{+}$concentration in the system was $0.10 \mathrm{~mol} / \mathrm{L}$. With addition of acid, $\mathrm{H}^{+}$concentration in the system was increased to $0.75 \mathrm{~mol} / \mathrm{L}$. Esterification is a reversible reaction and $\mathrm{H}^{+}$concentration determines the direction of reaction at equilibrium and thus affecting the rate of reaction or rate of conversion. The low conversion rate of FFAs to biodiesel in the esterification reaction without acid addition would be due to the low concentration of $\mathrm{H}^{+}$. In order to determine the ideal reaction time, experiment was prolonged from $24 \mathrm{~h}$ to 48 and $72 \mathrm{~h}$, as a result the biodiesel yield ( $\mathrm{g}$ FAMEs/g FFA added) was increased from $32.1 \%$ to $38.7 \%$ and $39.1 \%$, respectively. This suggested that the reaction reached its 
Table 2

Free fatty acid recovery from crude glycerol.

\begin{tabular}{|c|c|c|c|c|c|c|}
\hline Sample & $\begin{array}{l}\text { Crude glycerol } \\
(\mathrm{mL})\end{array}$ & $\begin{array}{l}\text { Acid }\left(\mathrm{H}_{3} \mathrm{PO}_{4}\right) \text { addition } \\
\text { amount }(\mathrm{mL})\end{array}$ & $\mathrm{pH}$ & FFA (g) & $\begin{array}{l}\text { FFA recovery } \\
\text { efficiency }(\%)\end{array}$ & $\begin{array}{l}\text { Glycerol content } \\
(\% \mathrm{w} / \mathrm{w})\end{array}$ \\
\hline 1 & 40 & 1 & 6.60 & 1.32 & 5.5 & $43.11 \pm 0.41$ \\
\hline 2 & 40 & 2 & 3.93 & 8.04 & 99.2 & $54.96 \pm 0.24$ \\
\hline 3 & 40 & 3 & 3.55 & 8.04 & 99.2 & $53.66 \pm 0.38$ \\
\hline 4 & 40 & 4 & 3.22 & 8.05 & 99.3 & $52.49 \pm 0.16$ \\
\hline 5 & 40 & 5 & 3.16 & 8.06 & 99.4 & $51.34 \pm 0.25$ \\
\hline 6 & 40 & 6 & 3.14 & 8.08 & 99.7 & $50.25 \pm 0.22$ \\
\hline 7 & 40 & 7 & 2.97 & 8.09 & 99.8 & $49.26 \pm 0.19$ \\
\hline 8 & 40 & 8 & 2.76 & 8.09 & 99.8 & $48.33 \pm 0.36$ \\
\hline 9 & 40 & 9 & 2.74 & 8.09 & 99.8 & $47.12 \pm 0.22$ \\
\hline 10 & 40 & 10 & 2.70 & 8.09 & 99.8 & $46.18 \pm 0.20$ \\
\hline
\end{tabular}

equilibrium in about $48 \mathrm{~h}$ under the condition of addition of $5 \mathrm{~mL}$ methanol per $0.2 \mathrm{~g}$ FFAs, catalyst amount of $0.1 \mathrm{~mol} \mathrm{H}^{+} / \mathrm{L}$, and reaction temperature of $50{ }^{\circ} \mathrm{C}$. Even though, the biodiesel yield increase to $38.7 \%$ after $48 \mathrm{~h}$ reaction, but it is much lower than that of the esterification with acid addition after only $24 \mathrm{~h}$ reaction, which was $90.8 \%$. It indicates that acid addition as catalyst is still required in order to make the process acceptable in practice when considering for utilization of the recovered FFA from crude glycerol for biodiesel production.

The obtained biodiesel contains mainly C18 and C16 with little amount of $\mathrm{C} 14$. In the reaction without acid (as catalyst) addition, FAMEs consists of $58.3 \% \mathrm{C} 18,37.1 \% \mathrm{C} 16$, and $2.9 \% \mathrm{C} 14$, and the saturation fatty acid degree was $56.4 \%$. In case with acid (as catalyst) addition, FAMEs contains $62.5 \%$ C18, 27.9\% C16, and 0.7\% C14 with saturation fatty acid degree of 66.2\%. FAMEs produced from FFA are similar as biodiesel produced from palm oil (55-68\% C18 and 32$45 \%$ C16 with saturation fatty acid degree of 50-55\%) (Ekpa et al., 1994; Verma et al., 2016). It suggested that the FAMEs generated are suitable to use as biodiesel.

\subsection{Effect of glycerol type on the biomass and lipid production}

T. oleaginosus could used crude glycerol but high glycerol concentration would inhibit cell growth (Liang et al., 2010a; Meesters et al.. 1996). The optimal glycerol concentration for cell growth was between 20 and $40 \mathrm{~g} / \mathrm{L}$ (Liang et al., 2010a; Meesters et al., 1996). In fact, carbon to nitrogen $(C / N)$ ratio has great impact on lipid accumulation. As reported, the optimal $\mathrm{C} / \mathrm{N}$ ratio for $T$. oleaginosus growth and lipid production was about 30 (Hassan et al., 1996; Liang et al., 2010a; Ryu et al., 2013). The aim of the study is to produce lipid with glycerol. To investigate glycerol type (crude glycerol, purified glycerol and pure glycerol) effect on cell growth and lipid production, the glycerol concentration of $25 \mathrm{~g} / \mathrm{L}$ was employed in the work as it is between 20 and $40 \mathrm{~g} / \mathrm{L}$ as well as made that the $\mathrm{C} / \mathrm{N}$ ratio of the medium was around 30 $(\mathrm{N}=0.3 \mathrm{~g} / \mathrm{L})$ (Ryu et al., 2013).

Pure, purified, and crude glycerol were used as carbon source for lipid production from T. oleaginosus. A lag period was observed in biomass growth (Fig. 2), which could be due to the fact that the inocula were not grown in the similar composition medium as the pre-culture medium, and thus an adaptation period may be required by the strain when transferred to the new medium (Gong et al., 2016; Xu et al., 2012). In order to minimize the lag period, the inocula should be produced in the similar medium as the production medium.

The fermentations continued $120 \mathrm{~h}$, and samples were taken for determining glycerol, biomass and lipid. The glycerol was completed consumed within $72 \mathrm{~h}$ fermentation and the biomass concentration and lipid content rapidly increased during the period for the case of pure and purified glycerol (Fig. 2). The biomass concentration of pure and purified glycerol fermentation reached the highest at $72 \mathrm{~h}$, which were $10.90 \mathrm{~g} / \mathrm{L}$ for pure glycerol and $10.32 \mathrm{~g} / \mathrm{L}$ for purified glycerol. In crude glycerol fermentation, the highest biomass concentration $(7.58 \mathrm{~g} / \mathrm{L})$ also took place at $72 \mathrm{~h}$. The highest maximum specific growth rate ( $\mu$ max) occurred in the fermentation with pure glycerol $\left(0.036 \mathrm{~h}^{-}\right)$as raw material followed by $25 \mathrm{~g} / \mathrm{L}$ purified glycerol $\left(0.034 \mathrm{~h}^{-}\right)$and crude glycerol $\left(0.025 \mathrm{~h}^{-}\right)$(Table 3).

The pure glycerol was slightly better than purified glycerol in terms of biomass production and maximum specific growth rate. Unlike pure glycerol, methanol is present in the purified glycerol. However, it wouldn't be the cause of the slightly low biomass concentration observed in purified glycerol $(10.32 \mathrm{~g} / \mathrm{L})$ comparing to that in pure glycerol $(10.90 \mathrm{~g} / \mathrm{L})$ cultivation. The boiling point of methanol is $65^{\circ} \mathrm{C}$ and sterilization of the medium by autoclaving at $121^{\circ} \mathrm{C}$ for 15 min will eliminate the methanol from the medium (Pyle et al., 2008). In fact, purified glycerol also contains metals and others impurities which are derived from feedstock oil or from the chemicals that are added during the biodiesel production process. It was reported that metals had negative impact on cell growth (Liang et al., 2010a; Pyle et al., 2008). Hence, the impurities in purified glycerol may inhibit biomass growth and lead to lower biomass density than that in pure glycerol (Capone et al., 1983; Polburee et al., 2015).

Compared to the biomass concentration in the fermentation with purified and pure glycerol at $72 \mathrm{~h}$, crude glycerol showed inhibition on cell growth. Similar trend was reported by other researchers (Cerón-García et al., 2013; Liang et al., 2010a; Polburee et al., 2015). In crude glycerol, soap content was around $21 \% \mathrm{w} / \mathrm{w}$. Both the soap and the cell surface are polar, and thus the soap could easily attach to the cell's surface, which can cause the inhibition of the nutrients transfer (Athalye et al., 2009; Sarma et al., 2014). The purified glycerol was obtained from crude glycerol after soap removal. This would be the reason of the higher biomass density observed in the purified glycerol than that in crude glycerol (Table 3).

During fermentation, lipid was rapidly accumulated in the cells from 0 to $72 \mathrm{~h}$ and the maximum lipid content was observed at $72 \mathrm{~h}$, which were $49 \%$ for pure glycerol and $44 \%$ for purified glycerol, respectively, (Fig. 2). After the glycerol consumed up, biomass concentration and lipid content gradually went down which would be due to that lipid were degraded by cells as energy for maintaining their activities. In the cultivation with the initial crude glycerol concentration of $25 \mathrm{~g} / \mathrm{L}$, there was still glycerol left unused at the end of the fermentation $(120 \mathrm{~h})$. During fermentation with crude glycerol, the $\mathrm{pH}$ of the broth was gradually decreasing from 6.5 to 5.1. As the $\mathrm{pH}$ of the fermentation broth went down, soap in the crude glycerol could be converted to FFA. However, the soap and FFA amount in the sample were low (both were less than $0.08 \mathrm{~g}$ in $5 \mathrm{~mL}$ ), and thus they were not detected during analysis. According to other report, $T$. oleaginosus was capable of assimilate FFA (Yang et al., 2015), and thus the strain might start to utilize FFA 

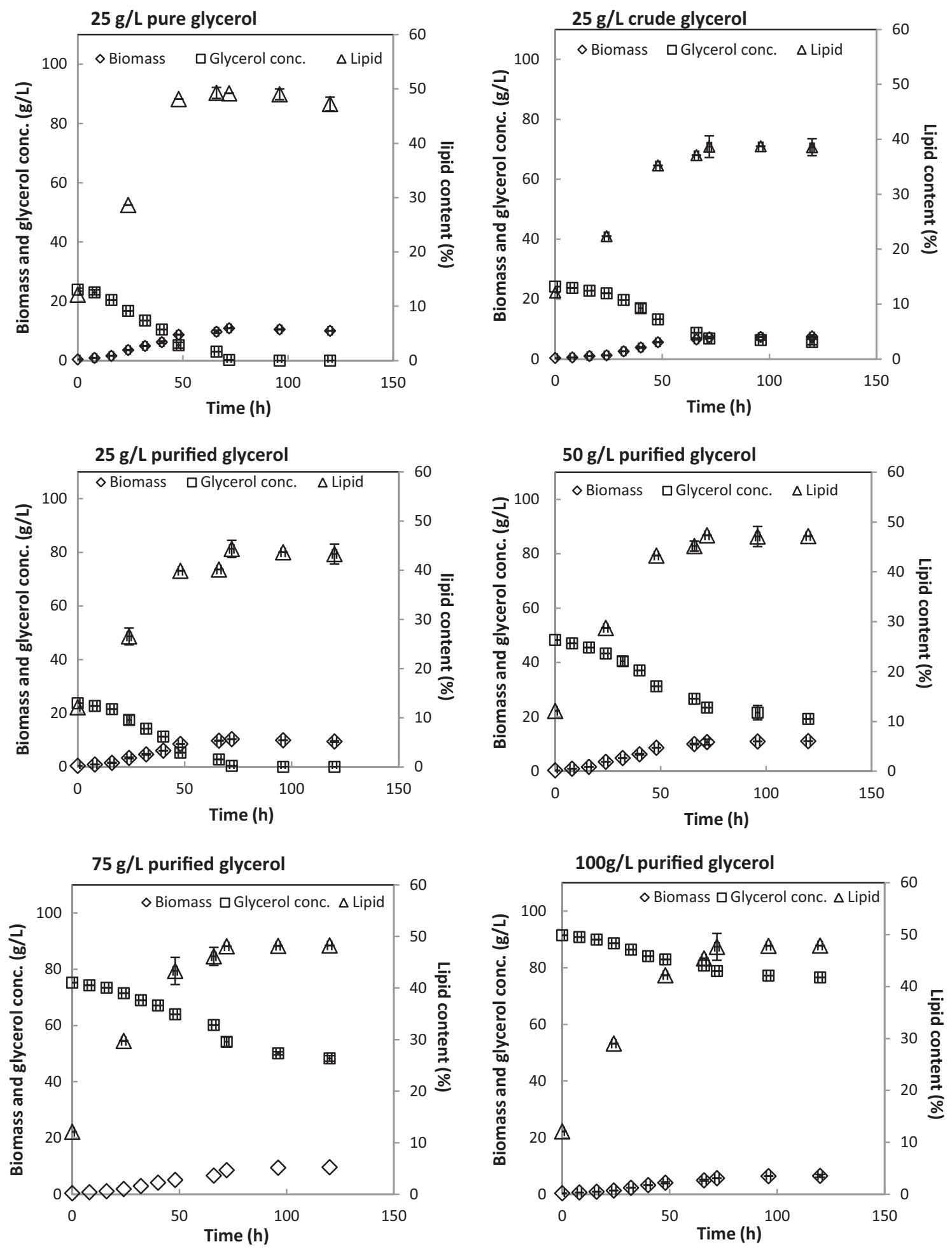

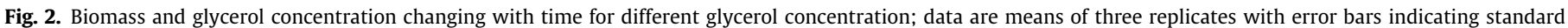
deviations.

as carbon source as well, which led to the glycerol consumption became slowly.

From 72 to $120 \mathrm{~h}$, biomass concentration and lipid content declined (in pure and purified glycerol fermentation) or kept stable (in crude glycerol fermentation), which suggested that the fermentation could be stopped at $72 \mathrm{~h}$ in order to avoid lipid consumption and waste energy (Fig. 2). The lipid yield and lipid productivity were $0.22 \mathrm{~g} \mathrm{lipid} / \mathrm{g}$ glycerol and $1.79 \mathrm{~g} / \mathrm{L} / \mathrm{d}$ for pure glycerol, $0.18 \mathrm{~g}$ lipid $/ \mathrm{g}$ glycerol and $1.52 \mathrm{~g} / \mathrm{L} / \mathrm{d}$ for purified glycerol, and $0.15 \mathrm{~g} \mathrm{lipid} / \mathrm{g}$ glycerol and $0.97 \mathrm{~g} / \mathrm{L} / \mathrm{d}$ for crude glycerol, respectively (Table 3 ). Biomass and lipid yields reveal the carbon utilization efficiency by microbes. The biomass $\left(Y_{x} / G\right)$ and lipid $\left(Y_{L} / G\right)$ yields of $T$. oleaginosus while grown in different types of glycerol at $25 \mathrm{~g} / \mathrm{L}$ concentration displayed the following trend, pure 
Table 3

Growth and lipids production parameters for T. oleaginosus grown in different types of glycerol.

\begin{tabular}{|c|c|c|c|c|c|c|c|c|c|c|c|c|}
\hline Glycerol type & Gly $_{0}(\mathrm{~g} / \mathrm{L})$ & $\mathrm{C} / \mathrm{N}$ ratio & Time (h) & $\operatorname{Gly}_{\mathrm{t}}(\mathrm{g} / \mathrm{L})$ & $X(g / L)$ & $\begin{array}{l}P_{X / V-T} \\
(g / L-d)\end{array}$ & $\mathrm{L}(\mathrm{g} / \mathrm{L})$ & $\begin{array}{l}\mathrm{P}_{\mathrm{L} / \mathrm{V}-\mathrm{T}} \\
(\mathrm{g} / \mathrm{L}-\mathrm{d})\end{array}$ & $\mu(/ h)$ & $Y_{L / X}(g / g)$ & $Y_{X / G}(g / g)$ & $\mathrm{Y}_{\mathrm{L} / \mathrm{G}}(\mathrm{g} / \mathrm{g})$ \\
\hline Pure glycerol & 25 & 90 & 72 & $0.17 \pm 0.04$ & $10.90 \pm 0.07$ & 3.63 & $5.36 \pm 0.03$ & 1.79 & 0.036 & $0.49 \pm 0.05$ & $0.44 \pm 0.01$ & $0.22 \pm 0.00$ \\
\hline Crude glycerol & 25 & 90 & 72 & $5.66 \pm 0.91$ & $7.58 \pm 0.44$ & 2.53 & $2.92 \pm 0.01$ & 0.97 & 0.025 & $0.39 \pm 0.01$ & $0.39 \pm 0.03$ & $0.15 \pm 0.01$ \\
\hline \multirow[t]{4}{*}{ Purified glycerol } & 25 & 90 & 72 & $0.33 \pm 0.02$ & $10.32 \pm 0.05$ & 3.44 & $4.57 \pm 0.05$ & 1.52 & 0.034 & $0.44 \pm 0.01$ & $0.42 \pm 0.02$ & $0.18 \pm 0.00$ \\
\hline & 50 & 180 & 72 & $22.25 \pm 0.05$ & $10.75 \pm 0.02$ & 3.69 & $5.24 \pm 0.02$ & 1.74 & 0.035 & $0.47 \pm 0.02$ & $0.40 \pm 0.02$ & $0.19 \pm 0.00$ \\
\hline & 75 & 270 & 72 & $49.31 \pm 0.99$ & $9.61 \pm 0.5$ & 3.20 & $4.63 \pm 0.00$ & 1.54 & 0.021 & $0.48 \pm 0.01$ & $0.37 \pm 0.02$ & $0.18 \pm 0.02$ \\
\hline & 100 & 360 & 72 & $76.59 \pm 0.05$ & $6.48 \pm 0.03$ & 2.16 & $3.10 \pm 0.03$ & 1.03 & 0.019 & $0.48 \pm 0.01$ & $0.28 \pm 0.01$ & $0.13 \pm 0.00$ \\
\hline
\end{tabular}

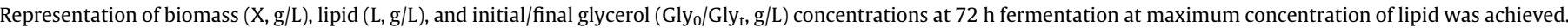

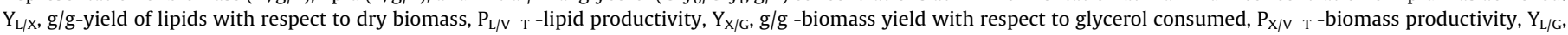

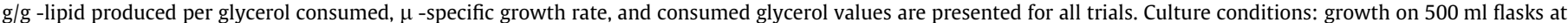
$170 \mathrm{rpm}$ and $\mathrm{T}=28^{\circ} \mathrm{C}$ with initial $\mathrm{pH} 6.5 \pm 0.1$.

glycerol > purified glycerol > crude glycerol (Table 3). Similar trend was also reported by other researchers: Liang et al. (2010a) found that pure glycerol as carbon source was the superior to crude glycerol and purified glycerol in terms of lipid accumulation in $T$. oleaginosus, and Papanikolaou and Aggelis (2002) also reported that pure glycerol was better than the purified and crude glycerol as carbon source for lipid accumulation in Y. Tipolytica (an oleaginous yeast) (Liang et al., 2010b; Papanikolaou and Aggelis, 2002). As the strain employed in the fermentations were the same, it indicates that pure glycerol as carbon for lipid production was better than the purified one, and the purified one was better than the crude glycerol. However, the lipid productivity showed that the purified glycerol had similar performance as the pure glycerol, and much superior than the crude glycerol. It indicates that the purified glycerol would be promising carbon source for lipid production from $T$. oleaginosus.

\subsection{Effect of glycerol concentration on the biomass and lipid production}

Purified glycerol was superior on biomass and lipid production by $T$. oleaginosus compared to crude glycerol as carbon source (Table 3); therefore, purified glycerol was further used to investigate glycerol concentration effect on the biomass and lipid production from T. oleaginosus. With glycerol concentration of $25 \mathrm{~g} / \mathrm{L}$, the glycerol was completed consumed with $72 \mathrm{~h}$ in purified glycerol fermentation, and biomass concentration and lipid content started to drop after $72 \mathrm{~h}$. In order to enhance biomass and lipid production and prevent the inhibition on cell growth and lipid accumulation that could be caused due to the low carbon concentration, glycerol concentration of 50,75 , and $100 \mathrm{~g} / \mathrm{L}$ were studied.

The biomass concentration increased with fermentation time proceeding at glycerol concentration of $25,50,75$, and $100 \mathrm{~g} / \mathrm{L}$ (Fig. 2). Increase in glycerol concentration from 25 to $50 \mathrm{~g} / \mathrm{L}$, the maximum biomass concentration slightly increased, while further increase in glycerol concentration the biomass concentration was significantly decreased (Table 3). Biomass yield decreased with the increase of the purified glycerol concentration, and the highest value was $0.42 \mathrm{~g} / \mathrm{g}$ glycerol consumed at $25 \mathrm{~g} / \mathrm{L}$ and the lowest was $0.28 \mathrm{~g} / \mathrm{g}$ glycerol consumed at $100 \mathrm{~g} / \mathrm{L}$ glycerol concentration. A decrease in biomass concentration at high glycerol concentration was due to substrate inhibition. Similar results have been reported by other researchers (Meesters et al., 1996). In their study, the growth of Cryptococcus curvatus (the previous name of T. oleaginosus) was restricted when the concentration of glycerol was higher than $64 \mathrm{~g} / \mathrm{L}$. An inhibitory impact of high glycerol concentration $(>60 \mathrm{~g} / \mathrm{L})$ on growth of Schizochytrium limacinum (oleaginous microalgae) was also observed (Liang et al., 2010b). On the other hand, oleaginous yeast Yarrowia lipolytica was not influenced by glycerol concentration in the range from 20 to $164 \mathrm{~g} / \mathrm{L}$ (Papanikolaou and Aggelis, 2002). For microalgae cultivation, the maximum biomass density (around $14 \mathrm{~g} / \mathrm{L}$ ) was obtained at a wide glycerol concentration range (from 35 to $85 \mathrm{~g} / \mathrm{L}$ ) (Liang et al., 2010a). Glycerol concentration effect on biomass production occurs not only with respect to different types of microorganisms (microalgae or yeast) used to cultivate, but also in the same types of microorganisms. It indicates that each microorganism has their own feature in utilization of glycerol. The maximum biomass density (around $10.75 \mathrm{~g} / \mathrm{L}$ ) was obtained at glycerol concentration of $50 \mathrm{~g} / \mathrm{L}$ after $72 \mathrm{~h}$ fermentation, which was similar as that in the fermentation with $25 \mathrm{~g} / \mathrm{L}$ pure glycerol $(10.90 \mathrm{~g} / \mathrm{L})$ or $25 \mathrm{~g} / \mathrm{L}$ of purified glycerol $(10.32 \mathrm{~g} / \mathrm{L})$ in $72 \mathrm{~h}$. It indicated that increase in glycerol concentration did not appreciably increase the biomass concentration.

The lipid yield were almost the same in the fermentation with 25 (0.18 g lipid/g glycerol), 50 ( $0.19 \mathrm{~g}$ lipid/g glycerol), and 75 ( $0.18 \mathrm{~g}$ lipid/g glycerol) g/L glycerol concentration, but it was substantially decreased to $0.13 \mathrm{~g} / \mathrm{g}$ after glycerol concentration increased to $100 \mathrm{~g} / \mathrm{L}$ (Table 3). The lipid productivity was $1.52 \mathrm{~g} / \mathrm{L} /$ d for $25 \mathrm{~g} / \mathrm{L}, 1.74 \mathrm{~g} / \mathrm{L} / \mathrm{d}$ for $50 \mathrm{~g} / \mathrm{L}, 1.54 \mathrm{~g} / \mathrm{L} / \mathrm{d}$ for $75 \mathrm{~g} / \mathrm{L}$, and $1.03 \mathrm{~g} / \mathrm{L} / \mathrm{d}$ for $100 \mathrm{~g} / \mathrm{L}$, respectively. The results were different from reported by other researchers, in which glycerol concentration from 90 to $100 \mathrm{~g} / \mathrm{L}$ gave the highest lipid yield and productivity (Kitcha and Cheirsilp, 2011; Yen et al., 2012). The difference could be due to the difference of the strains employed and the composition of the glycerol utilized (Polburee et al., 2015; Saenge et al., 2011; Yen et al., 2012). It was expected that the lipid yield would enhanced with the increase of carbon concentration; however, the results obtained in the study showed that high carbon concentration (75 and $100 \mathrm{~g} / \mathrm{L}$ glycerol) has inhibited the lipid production. It was observed that the glycerol consumption became slow even through there was still plenty of glycerol left in the medium, which was $23.43 \mathrm{~g} / \mathrm{L}$ and $54.23 \mathrm{~g} / \mathrm{L}$ in the fermentation with $50 \mathrm{~g} / \mathrm{L}$ and $75 \mathrm{~g} / \mathrm{L}$ glycerol concentration, respectively. This may be due to the fact that inhibitors (such as toxic protein or ethanol) maybe produced along with cell growth (Nevoigt, 2008). In order to eliminate the inhibition problem, fed-batch process approach can be adopted instead of the batch process. The concentrations of inhibitors are diluted during feeding process of a fed-batch culture. Some researchers have reported that very high biomass concentration (more than $100 \mathrm{~g} / \mathrm{L}$ ) were achieved in fed batch fermentation (Meesters et al., 1996).

In this study, it was found that the purified glycerol has great potential for lipid production from microbe. The lipid yield of different strains cultivated in glycerol medium by different researchers was summarized in Table 4. It clearly displayed that the lipid yield obtained in this study was comparable with other studies. Thus, purified glycerol could be utilized as a carbon source for lipid 
Table 4

Glycerol concentration effect on lipid accumulation.

\begin{tabular}{|c|c|c|c|c|}
\hline Strains & Glycerol type & Optimal glycerol conc. (g/L) & Lipid yield (g/g glycerol) & References \\
\hline Aspergillus niger LFMB1 & Crude glycerol & 60 & 0.20 & (André et al., 2009) \\
\hline Aspergillus niger NRRL 364 & Crude glycerol & 60 & 0.21 & (André et al., 2009) \\
\hline Schizochytrium limacinum & Purified glycerol & 35 & 0.26 & (Liang et al., 2010b) \\
\hline Kodamaea ohmeri & Crude glycerol & 100 & 0.20 & (Kitcha and Cheirsilp 2011) \\
\hline Trichosporonoides spathulata & Crude glycerol & 100 & 0.18 & (Kitcha and Cheirsilp 2011) \\
\hline Rhodotorula sp. LFMB 22 & Crude glycerol & 30 & 0.10 & (Chatzifragkou et al., 2011) \\
\hline Chlorella protothecoides & Crude glycerol & 30 & 0.33 & (O'Grady and Morgan 2011) \\
\hline Rhodotorula glutinis & Crude glycerol & 100 & 0.10 & (Saenge et al., 2011) \\
\hline Rhodosporidium toruloides & Crude glycerol & 50 & 0.15 & (Xu et al., 2012) \\
\hline Rhodotorula glutinis & Crude glycerol & 90 & 0.13 & (Yen et al., 2012) \\
\hline Trichosporon oleaginosus & Purified glycerol & 50 & 0.19 & This study \\
\hline
\end{tabular}

production by $T$. oleaginosus with the concentration between 25 and $50 \mathrm{~g} / \mathrm{L}$.

\subsection{Fatty acid profile of T. oleaginous biomass extracted lipid}

The FFAs content were $0.44 \%, 1.19 \%, 0.46 \%, 0.44 \%, 0.43 \%$, and $0.44 \% \mathrm{w} / \mathrm{w}$ on lipids derived from $T$. oleaginosus obtained after $72 \mathrm{~h}$ cultivation with $25 \mathrm{~g} / \mathrm{L}$ pure glycerol, $25 \mathrm{~g} / \mathrm{L}$ crude glycerol, and $25,50,75$ and $100 \mathrm{~g} / \mathrm{L}$ purified glycerol, respectively. The FFA content obtained in this study (less than $1.2 \% \mathrm{w} / \mathrm{w}$ lipids) was significantly different from those $(9 \% \mathrm{w} / \mathrm{w}$ lipids) observed by other researchers (Thiru et al., 2011). This would be due to the different treatment of biomass. In this study, the wet biomass was dried by lyophilisation, which preserved the nature of the lipids, and then lipids were extracted with solvent. The extracted fresh lipid was directly used to determine FFA content without storage, which prevented the risk of triacylglycerol (TAG) decomposition to FFAs. In the study of Thiru et al. (2011), the fermented broth was homogenized (the risk of degradation) followed by solvent extraction of lipid from wet yeast cells with no indication if fresh lipid was used for FFA content determination. A study has reported that storage of microbial lipid above $0{ }^{\circ} \mathrm{C}$ for $24 \mathrm{~h}$ could increase the FFA content from less than $0.1-20 \% \mathrm{w} / \mathrm{w}$ lipid and decrease the TAG content from 72 to $51 \% \mathrm{w} / \mathrm{w}$ lipid (Chen et al., 2012). It clearly indicated that TAG was degraded to FFA during storage. Therefore, the high FFA content observation in other study would be due to the storage of the biomass which resulted in TAG degradation to FFA. While in our study, fresh biomass (without storage) was used in the lipid extraction.

Comparing the composition of lipid obtained using different types of glycerol, relatively high FFA content was found when crude glycerol $(1.19 \% \mathrm{w} / \mathrm{w}$ total lipid) was used as raw material. This could be due to the presence of FFA in crude glycerol. As discussed above, FFA existed in the crude glycerol medium due to soap dissociation at $\mathrm{pH} 6.5$ (Table 2); therefore, FFA could attach onto the cell surface. During cell harvesting, washing was performed twice with distilled water, yet FFA would not be dissolved in water and would remain stick to the cell surface. Thereafter, the FFA attached on the surface of cells could be extracted along with the lipid during organic solvent extraction process. Thus, the FFA content of the biomass obtained from the cultivation with crude glycerol was higher compared to that with purified and pure glycerol. The FFA content of lipid extracted from biomass grown on pure and purified glycerol was almost the same, and the purified glycerol concentration $(25-100 \mathrm{~g} / \mathrm{L})$ didn't impact the FFA content $(0.46 \%, 0.44 \%, 0.43 \%$, and $0.44 \% \mathrm{w} / \mathrm{w}$ total lipid for $25,50,75$ and $100 \mathrm{~g} / \mathrm{L}$ purified glycerol, respectively). For all extracted lipids irrespective of glycerol type used to grow the biomass, the FFA content was lower than $2 \% \mathrm{w} / \mathrm{w}$ lipid, hence alkaline $\mathrm{NaOH}$ could be used as catalyst in the trans-esterification process.
The fatty acid profile of the lipid extracted from biomass was shown in Table 5. The majority of fatty acids were C16:0 and C18:1, which was similar to Jatropha seed oil (currently used in commercial biodiesel production practice in some countries). It suggests that the lipid from $T$. oleaginosus cultivated with glycerol is suitable in usage as biodiesel production feedstock. The saturation degree (the sum of $\mathrm{Cn}: 0$ ) of the lipid was around $30-40 \%$ $\mathrm{w} / \mathrm{w}$ total lipid. It reveals that the biodiesel produced from the lipid derived from purified glycerol had high oxidation stability.

\subsection{The productivity of the proposed process}

In this study, the crude glycerol generated from biodiesel production was used to produce biodiesel. There were two parts on biodiesel production: (1) the FFA recovered from crude glycerol purification step was converted to biodiesel through esterification; (2) the purified crude glycerol was used as carbon for oleaginous yeast cultivation, and the lipid accumulated in the yeast was then transferred to biodiesel. Based on the results (Table 2), $8.04 \mathrm{~g}$ of FFA could be recovered from $40 \mathrm{~mL}$ of crude glycerol, and the biodiesel yield was $90.8 \%$ with acid as catalyst after 24 h esterification of FFA. It suggested that $182.51 \mathrm{~g}$ of biodiesel can be generated from FFA recovered from $1 \mathrm{~L}$ of crude glycerol. The $1 \mathrm{~kg}$ crude glycerol contains $318 \mathrm{~g}$ glycerol (Table 1 ), accordingly, $1 \mathrm{~L}$ crude glycerol will contain $341.21 \mathrm{~g}$ glycerol as the density of crude glycerol is $1.073 \mathrm{~kg} / \mathrm{L}$. The fermentation studies revealed that the lipid yield from glycerol could reach $0.19 \mathrm{~g}$ lipid/g glycerol after $72 \mathrm{~h}$ (Tables 3 and 4), hence, the biodiesel obtained from fermentation with glycerol as carbon would be around $63.53 \mathrm{~g}$ $(=0.19 \times 341.21 \times 98 \% ; 98 \%$ is the trans-esterification efficiency according to our study). Overall, in this study, the $1 \mathrm{~L}$ crude glycerol could produce $246.04 \mathrm{~g}$ biodiesel within $72 \mathrm{~h}$ which includes $182.51 \mathrm{~g}$ biodiesel from recovered FFA from crude glycerol $(24 \mathrm{~h})$ and $63.53 \mathrm{~g}$ biodiesel from glycerol fermentation $(72 \mathrm{~h})$. The first run of the process would take around $150 \mathrm{~h}$ (including crude glycerol purification, fermentation, and trans-esterification). However, it would be only $72 \mathrm{~h}$ required in long term operation as fermentation is the limiting step in time demand and other part involving can be simultaneously performed during fermentation.

To the best of our knowledge, so far, the highest lipid yield from glycerol reported was $0.33 \mathrm{~g}$ lipid/g glycerol after $72 \mathrm{~h}$ fermentation (Table 4). It suggests that $1 \mathrm{~L}$ crude glycerol could maximum produce $110.35 \mathrm{~g}$ biodiesel from fermentation when considering that each step from fermentation to biodiesel formed all performs under the optimal condition. It is still lower than the biodiesel productivity from crude glycerol reported in this study, which could produce $246.04 \mathrm{~g}$ biodiesel from $1 \mathrm{~L}$ crude glycerol within $72 \mathrm{~h}$. It clearly indicates that the process in this study significantly enlarged crude glycerol to biodiesel productivity comparing that of using crude glycerol only for fermentation without recovering FFA and converting it to biodiesel. 
Table 5

Fatty acid profile of lipid from $T$. oleaginosus.

\begin{tabular}{|c|c|c|c|c|c|c|c|}
\hline \multirow{2}{*}{$\begin{array}{l}\text { Fatty } \\
\text { acid }\end{array}$} & \multicolumn{7}{|c|}{ Relative amount of total fatty acids (\% w/w) } \\
\hline & $\begin{array}{l}\text { Lipid from Pure } \\
\text { glycerol }(25 \mathrm{~g} / \mathrm{L})\end{array}$ & $\begin{array}{l}\text { Lipid from crude } \\
\text { glycerol }(25 \mathrm{~g} / \mathrm{L})\end{array}$ & $\begin{array}{l}\text { Lipid from purified } \\
\text { glycerol }(25 \mathrm{~g} / \mathrm{L})\end{array}$ & $\begin{array}{l}\text { Lipid from purified } \\
\text { glycerol }(50 \mathrm{~g} / \mathrm{L})\end{array}$ & $\begin{array}{l}\text { Lipid from purified } \\
\text { glycerol }(75 \mathrm{~g} / \mathrm{L})\end{array}$ & $\begin{array}{l}\text { Lipid from purified } \\
\text { glycerol }(100 \mathrm{~g} / \mathrm{L})\end{array}$ & $\begin{array}{l}\text { Jatropha } \\
\text { seed oil }\end{array}$ \\
\hline C14:0 & 0.1 & 2.2 & 0.1 & 0.3 & 0.1 & 0.1 & - \\
\hline C15:0 & 0.9 & 0.2 & 0.6 & 0.5 & 0.8 & 0.7 & - \\
\hline C16:0 & 19.3 & 22.6 & 20.1 & 21.0 & 20.7 & 20.2 & $12-20$ \\
\hline C16:1 & 1.0 & 0.6 & 0.8 & 0.5 & 0.9 & 0.7 & - \\
\hline C18:0 & 13.4 & 19.5 & 15.2 & 14.9 & 15.0 & 14.2 & $5.0-10$ \\
\hline C18:1 & 50.6 & 46.7 & 49.7 & 50.2 & 50.6 & 50.6 & $37-63$ \\
\hline C18:2 & 7.5 & 5.8 & 8.6 & 7.9 & 7.2 & 7.8 & 10-19 \\
\hline C18:3 & 0.39 & 0.42 & 0.33 & 0.40 & 0.51 & 0.39 & - \\
\hline C20:0 & 1.1 & 0.5 & 0.8 & 0.6 & 0.6 & 0.8 & - \\
\hline
\end{tabular}

a (Wassner et al., 2016).

\subsection{Mass and energy balance of the proposed process}

Conversion of crude glycerol to biodiesel is aimed to produce extra energy to the biodiesel production. In this study, the bio- diesel was produced from two parts including esterification of the FFA recovered from crude glycerol and trans-esterification of lipid accumulated in $T$. oleaginosus cultivated with the purified glycerol (after FFA recovery) (Fig. 1). Though, energy (biodiesel)
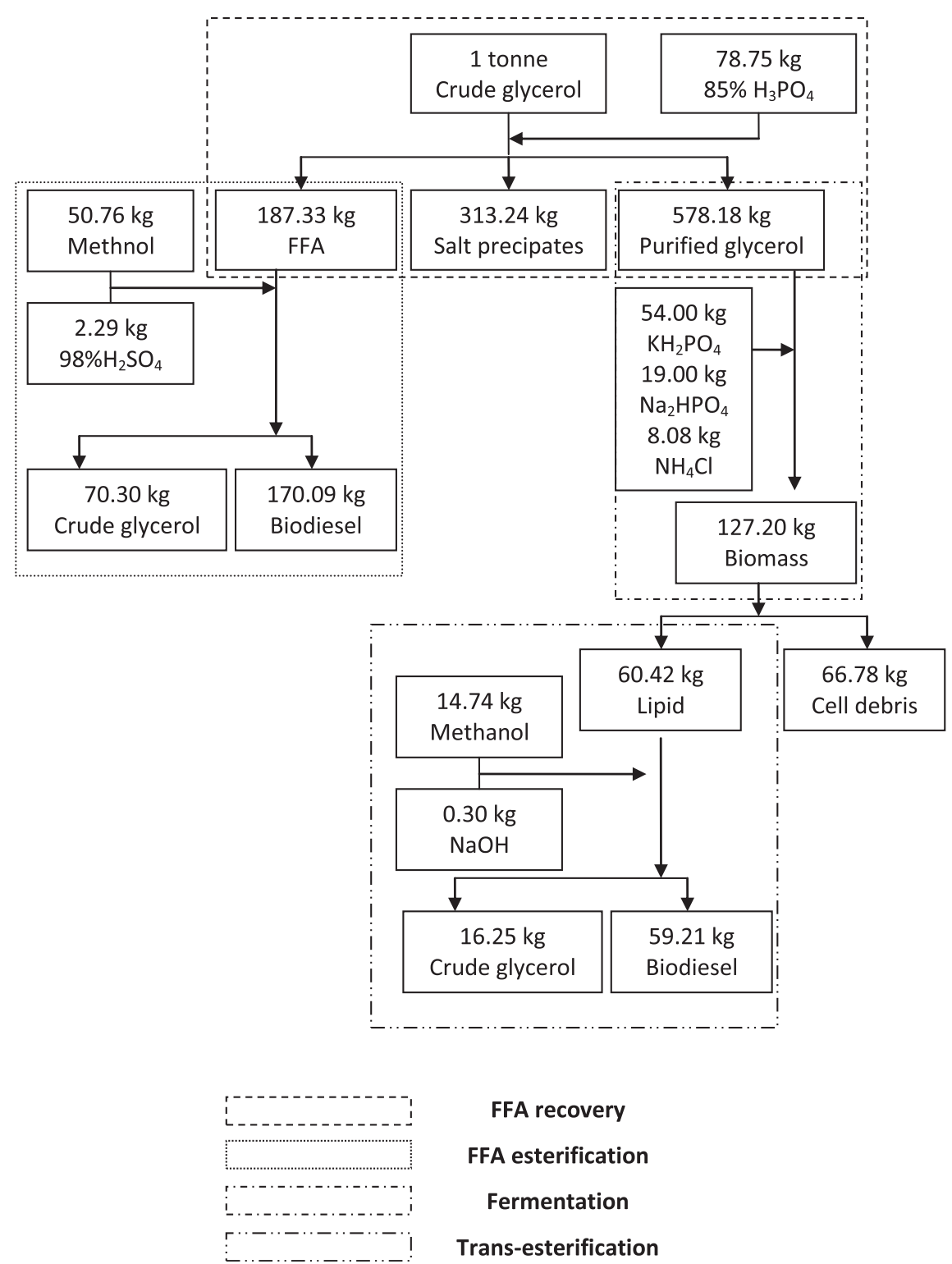

\section{FFA recovery}

FFA esterification

\section{Fermentation}

Trans-esterification

Fig. 3. The mass balance of biodiesel production from crude glycerol. 
was produced from the crude glycerol, energy was also consumed as the esterification, trans-esterification, and lipid production from the purified glycerol derived from crude glycerol, were energy consumption processes. The energy balance (=energy produced - energy consumed) of biodiesel production from crude glycerol is an important indicator to evaluate if the process is practically feasible. The energy balance was calculated based on 1 tonne of crude glycerol used to produce biodiesel. The mass and energy balance was shown in Fig. 3 and Table 6, respectively.

Table 6

Energy balance of biodiesel production from crude glycerol.

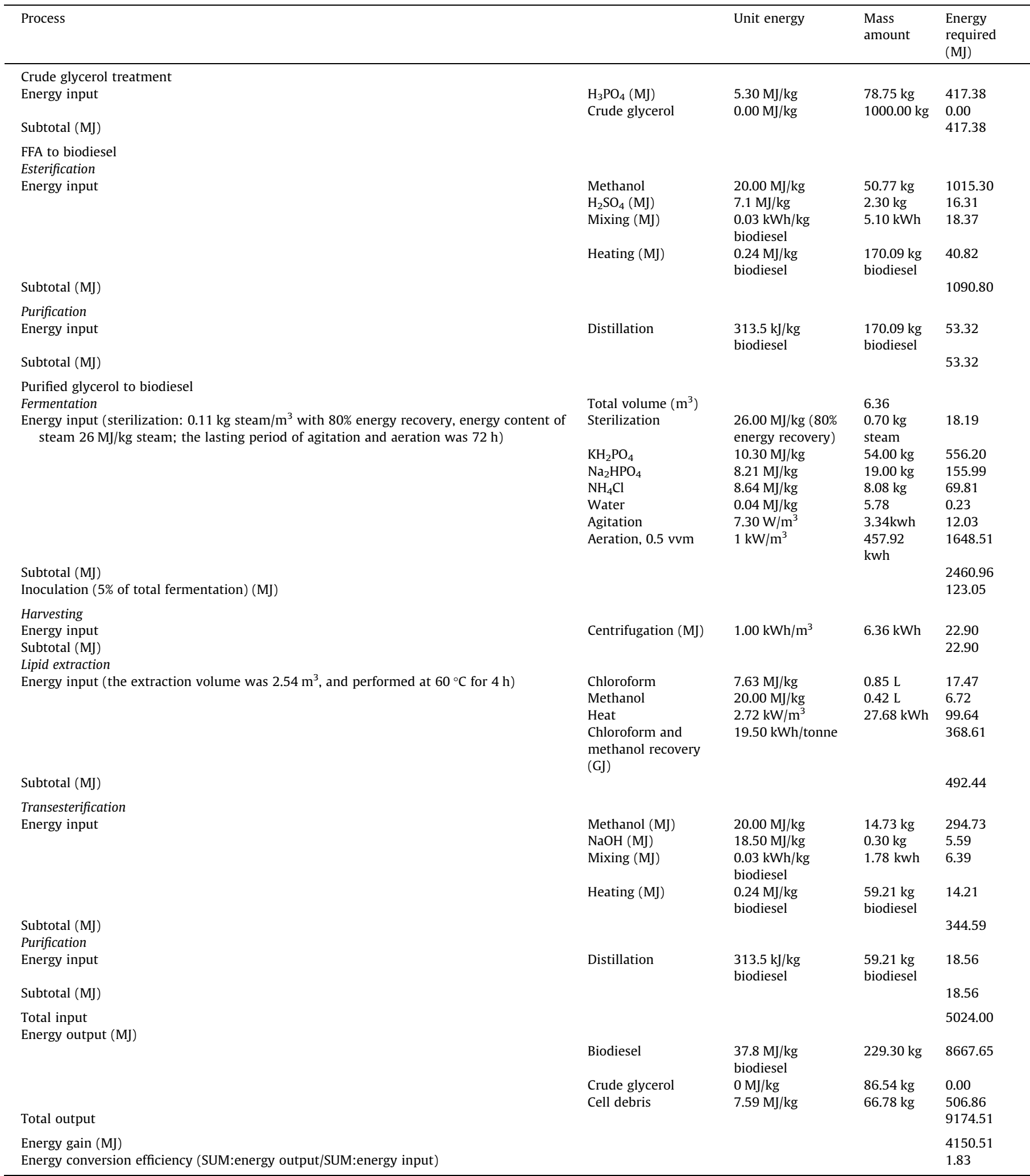


From the mass balance calculation, it can be seen that 1 tonne of crude glycerol could produce $229.30 \mathrm{~kg}$ biodiesel, $86.54 \mathrm{~kg}$ crude glycerol, and $66.78 \mathrm{~kg}$ cell debris (Fig. 3). The energy balance was calculated based on the mass balance study. In the energy balance study, assumptions were made: (1) the biodiesel production from crude glycerol took place in the biodiesel production industry (where crude glycerol was generated), which suggested that there was no energy input from the transportation of crude glycerol; (2) the energy input from the utilization of crude glycerol was zero and the crude glycerol generated in esterification and transesterification was also zero; (3) methanol and $\mathrm{H}_{2} \mathrm{SO}_{4}$ were not recovered after esterification and remained in crude glycerol; (4) the fermentation of $T$. oleaginosus for lipid production was conducted under aseptic condition, the power consumption was adopted from our previous study (Zhang et al., 2017); (5) the energy input in biomass harvesting, lipid extraction and transesterification was similarly estimated as utilized in our previous study (Zhang et al., 2017); (6) in the trans-esterification of lipid to biodiesel, methanol and $\mathrm{NaOH}$ were not recovered after the reaction; (7) the cell debris was assumed to be used as animal feed (Zhang et al., 2016).

The energy input during crude glycerol treatment namely FFA recovery was mainly from the utilization of $85 \% \mathrm{H}_{3} \mathrm{PO}_{4}$, which was $417.38 \mathrm{MJ}$. After FFA was separated from the crude glycerol, it was used to synthesize biodiesel through esterification with the addition of methanol and $\mathrm{H}_{2} \mathrm{SO}_{4}$ under heating. The energy input was from the utilization of methanol, $\mathrm{H}_{2} \mathrm{SO}_{4}$, and energy to provide the heating, which was $1090.80 \mathrm{MJ}$. After biodiesel generation, distillation was performed to purify the product and thus $53.32 \mathrm{MJ}$ of energy was consumed (Table 3 ).

In this study, the other part of biodiesel was produced from the lipid accumulated in $T$. oleaginosus cultivated with the purified glycerol obtained from crude glycerol after FFA recovery. It included the fermentation of $T$. oleaginosus, biomass harvesting, lipid extraction, trans-esterification, and biodiesel purification (Table 6). During fermentation, chemicals $\left(\mathrm{KH}_{2} \mathrm{PO}_{4}, \mathrm{Na}_{2} \mathrm{HPO}_{4}, \mathrm{NH}_{4}^{-}\right.$ $\mathrm{Cl}$ ) were added as nutrient source. Oxygen was supplied by aeration and agitation was used for mixing. The energy input in the fermentation was 2460.96 MJ plus $123.05 \mathrm{MJ}$ (pre-culture production). After fermentation, centrifugation (22.90 MJ) was performed to collect the biomass followed by extraction (492.44 MJ) with chloroform and methanol at $60^{\circ} \mathrm{C}$. The extracted lipid was then converted to biodiesel through trans-esterification which consumed 344.59 MJ. The produced biodiesel contained water, hence purification was employed, which had an energy input of 18.56 MJ. The total energy input of the biodiesel production from the purified glycerol derived from crude glycerol was 5024.00 MJ. The energy output of the processes was from the produced biodiesel (8667.65 MJ) and the generated cell debris (506.86 MJ). It was observed that the total energy output $(9174.51 \mathrm{MJ})$ was greater than the total energy input (5024.00 MJ). It indicates that utilization of crude glycerol with high soap content to produce biodiesel was an energy gain process, which was 4150.51 MJ. The energy conversion efficiency calculated by dividing the total energy input with the total energy output was 1.83 . The energy balance study revealed that converting the crude glycerol with high soap content to biodiesel through the method presented in this study (Fig. 1) was an energy feasible application of crude glycerol.

\subsection{Cost estimation of the proposed process}

The cost was estimated based on the similar assumption as in the energy balance and 1 tonne of crude glycerol used to produce biodiesel. The cost was mainly from the utilization of raw materials and utilities, equipment depreciation, labor, and laboratory/QC/QA. SuperPro Designer was employed to estimate the cost. The plant life span was set for 10 years, and the equipment depreciation was calculated. The chemical and equipment prices were adopted from the ICIS Pricing and IRON solutions Official Guides, respectively. The prices of electricity and labor were set at 0.10 US $\$ /$ $\mathrm{kWh}$ and $10 \mathrm{US} \$ / \mathrm{h}$. The annual production days were 330 per year.

Based on these assumptions, the biodiesel cost was 6.32 US $\$ /$ gal (=1.87 from raw materials US $\$+2.34$ US $\$$ from equipment depreciation +0.76 US $\$$ from utilities ++1.35 US $\$$ from labor), which was higher than the commercial biodiesel price (3.78 $\$$ /gal). It indicated that utilization of crude glycerol for biodiesel production was not cost acceptable on the basis of 1 tonne crude glycerol utilized with lipid yield of $0.19 \mathrm{~g} / \mathrm{g}$ glycerol and the fermentation time of $72 \mathrm{~h}$. There are several methods to reduce the biodiesel production cost, which are:

(1) The raw material cost was from the usage of nutrients and solvents. In fact, nutrients could be replaced by addition of waste such as sludge which has been reported to be potential nitrogen, phosphors, and trace elements (Zhang et al. 2017), which would reduce the cost.

(2) With the increase of the plant scale, the equipment depreciation and labor cost can be decreased, which can thus reduce the total production cost.

(3) Increase of lipid yield and reduce the fermentation time, the cost from the equipment depreciation, the labor, and the utilities can be reduced.

Overall, to make the process cost favourable, cheap nutrient source has to be supplied, fermentation has to be optimized, and plant scale should be increased.

\section{Conclusions}

This study has demonstrated that crude glycerol from the biodiesel production industry could be used for producing lipid which could be further converted to biodiesel. Due to the large amount soap content in the crude glycerol, simple purification was conducted to recover FFA from crude glycerol. The recovered FFA was, in fact, also good source for biodiesel production through esterification. The obtained purified glycerol performed similar as pure glycerol in biomass growth and lipid accumulation. The study has provided a method to maximize the productivity of crude glycerol to biodiesel. The energy balance study showed that the process could provide energy gain.

\section{Acknowledgments}

Sincere thanks are due to the Natural Sciences and Engineering Research Council of Canada (Grant A 4984, Strategic Grant- STPGP 412994-11, Canada Research Chair) for their financial support. The views and opinions expressed in this paper are those of the authors.

\section{References}

André, A., Chatzifragkou, A., Diamantopoulou, P., Sarris, D., Philippoussis, A., Galiotou-Panayotou, M., Komaitis, M., Papanikolaou, S., 2009. Biotechnological conversions of bio-diesel-derived crude glycerol by Yarrowia lipolytica strains. Eng. Life Sci. 9, 468-478.

Athalye, S.K., Garcia, R.A., Wen, Z., 2009. Use of biodiesel-derived crude glycerol for producing Eicosapentaenoic acid (EPA) by the fungus Pythium irregulare. J. Agric. Food Chem. 57, 2739-2744.

Lima, B. Insausti, M. Domini, C.E, Pistonesi, M.F. Ugulino de Araújo, M.C. Fernández Band, B.S., 2012. Automatized flow-batch method for fluorescent determination of free glycerol in biodiesel samples using on-line extraction. Talanta 89, 21-26.

Bondioli, P., Della Bella, L., 2005. An alternative spectrophotometric method for the determination of free glycerol in biodiesel. Eur. J. Lipid Sci. Technol. 107, 153157. 
Capone, D.G., Reese, D.D., Kiene, R.P., 1983. Effects of metals on methanogenesis, sulfate reduction, carbon dioxide evolution, and microbial biomass in anoxic salt marsh sediments. Appl. Environ. Microbiol. 45, 1586-1591.

Cerón-García, M.C., Macías-Sánchez, M.D., Sánchez-Mirón, A., García-Camacho, F., Molina-Grima, E., 2013. A process for biodiesel production involving the heterotrophic fermentation of Chlorella protothecoides with glycerol as the carbon source. Appl. Energy 103, 341-349.

Chatzifragkou, A., Makri, A., Belka, A., Bellou, S., Mavrou, M., Mastoridou, M., Mystrioti, P., Onjaro, G., Aggelis, G., Papanikolaou, S., 2011. Biotechnological conversions of biodiesel derived waste glycerol by yeast and fungal species. Energy 36, 1097-1108.

Chen, L., Liu, T., Zhang, W., Chen, X., Wang, J., 2012. Biodiesel production from algae oil high in free fatty acids by two-step catalytic conversion. Bioresour. Technol. $111,208-214$

Deeba, F., Pruthi, V., Negi, Y.S., 2016. Converting paper mill sludge into neutral lipids by oleaginous yeast Cryptococcus vishniaccii for biodiesel production. Bioresour. Technol. 213, 96-102.

Ekpa, O.D., Fubara, E.P., Morah, F.N.I., 1994. Variation in fatty acid composition of palm oils from two varieties of the oil palm (Eelaeis guineensis). J. Sci. Food Agric. 64, 483-486.

Folch, J., Lees, M., Sloane, S.G.H., 1957. A simple method for the isolation and purification of total lipides from animal tissues. J. Biol. Chem. 226, 497-509.

Gao, Z., Ma, Y., Wang, Q., Zhang, M., Wang, J., Liu, Y., 2016. Effect of crude glycerol impurities on lipid preparation by Rhodosporidium toruloides yeast 32489. Bioresour. Technol. 218, 373-379.

Gong, Z., Zhou, W., Shen, H., Zhao, Z.K., Yang, Z., Yan, J., Zhao, M., 2016. Co-utilization of corn stover hydrolysates and biodiesel-derived glycerol by Cryptococcus curvatus for lipid production. Bioresour. Technol. 219, 552-558.

Halim, R., Gladman, B., Danquah, M.K., Webley, P.A., 2011. Oil extraction from microalgae for biodiesel production. Bioresour. Technol. 102, 178-185.

Hansen, C.F., Hernandez, A., Mullan, B.P., Moore, K., Trezona-Murray, M., King, R.H., Pluske, J.R., 2009. A chemical analysis of samples of crude glycerol from the production of biodiesel in Australia, and the effects of feeding crude glycerol to growing-finishing pigs on performance, plasma metabolites and meat quality at slaughter. Anim. Prod. Sci. 49, 154-161.

Hassan, M., Blanc, P.J., Granger, L.-M., Pareilleux, A., Goma, G., 1996. Influence of nitrogen and iron limitations on lipid production by Cryptococcus curvatus grown in batch and fed-batch culture. Process Biochem. 31, 355-361.

Hu, S., Luo, X., Wan, C., Li, Y., 2012. Characterization of crude glycerol from biodiesel plants. J. Agric. Food Chem. 60, 5915-5921.

Kelly T. 2006. Crude glycerine and hot compost. Avaiable at <http://www.mailarchive.com/sustainablelorgbiofuel@lists.sustainablelists.org/msg63336.html> (accessed Dec. 2012).

Kitcha, S., Cheirsilp, B., 2011. Screening of oleaginous yeasts and optimization for lipid production using crude glycerol as a carbon source. Energy Proce. 9, $274-$ 282.

Liang, Y., Cui, Y., Trushenski, J., Blackburn, J.W., 2010a. Converting crude glycerol derived from yellow grease to lipids through yeast fermentation. Bioresource Technol. 101, 7581-7586.

Liang, Y., Sarkany, N., Cui, Y., Blackburn, J.W., 2010b. Batch stage study of lipid production from crude glycerol derived from yellow grease or animal fats through microalgal fermentation. Bioresour. Technol. 101, 6745-6750.

Lorenz, E., Runge, D., Marbà-Ardébol, A.-M., Schmacht, M., Stahl, U., Senz, M., 2017. Systematic development of a two-stage fed-batch process for lipid accumulation in Rhodotorula glutinis. J. Biotechnol. 246, 4-15.

Manosak, R., Limpattayanate, S., Hunsom, M., 2011. Sequential-refining of crude glycerol derived from waste used-oil methyl ester plant via a combined process of chemical and adsorption. Fuel Process. Technol. 92, 92-99.

Meesters, P.A.E.P., Huijberts, G.N.M., Eggink, G., 1996. High-cell-density cultivation of the lipid accumulating yeast Cryptococcus curvatus using glycerol as a carbon source. Appl. Microbiol. Biotechnol. 45, 575-579.

Nartker, S., Ammerman, M., Aurandt, J., Stogsdil, M., Hayden, O., Antle, C., 2014. Increasing biogas production from sewage sludge anaerobic co-digestion process by adding crude glycerol from biodiesel industry. Waste Manage. 34, 2567-2571.

Nevoigt, E., 2008. Progress in metabolic engineering of Saccharomyces cerevisiae. Microbiol. Mol. Biol. Rev. 72, 379-412.

O'Grady, J., Morgan, J., 2011. Heterotrophic growth and lipid production of Chlorella protothecoides on glycerol. Bioprocess. Biosyst. Eng. 34, 121-125.

Oliveira, J.V., Alves, M.M., Costa, J.C., 2015. Optimization of biogas production from Sargassum sp. using a design of experiments to assess the co-digestion with glycerol and waste frying oil. Bioresour. Technol. 175, 480-485.
Papanikolaou, S., Aggelis, G., 2002. Lipid production by Yarrowia lipolytica growing on industrial glycerol in a single-stage continuous culture. Bioresour. Technol. 82, 43-49.

Polburee, P., Yongmanitchai, W., Lertwattanasakul, N., Ohashi, T., Fujiyama, K., Limtong, S., 2015. Characterization of oleaginous yeasts accumulating high levels of lipid when cultivated in glycerol and their potential for lipid production from biodiesel-derived crude glycerol. Fungal Biol. 119, 1194 1204.

Pyle, D.J., Garcia, R.A., Wen, Z., 2008. Producing docosahexaenoic acid (DHA)-rich algae from biodiesel-derived crude glycerol: effects of impurities on DHA production and algal biomass composition. J. Agric. Food Chem. 56, $3933-$ 3939.

Ryu, B.-G., Kim, J., Kim, K., Choi, Y.-E., Han, J.-I., Yang, J.-W., 2013. High-cell-density cultivation of oleaginous yeast Cryptococcus curvatus for biodiesel production using organic waste from the brewery industry. Bioresource Technol. 135, 357364.

Saenge, C., Cheirsilp, B., Suksaroge, T.T., Bourtoom, T., 2011. Potential use of oleaginous red yeast Rhodotorula glutinis for the bioconversion of crude glycerol from biodiesel plant to lipids and carotenoids. Process Biochem. 46, $210-218$.

Sarma, S.J., Brar, S.K., Le Bihan, Y., Buelna, G., Soccol, C.R., 2014. Mitigation of the inhibitory effect of soap by magnesium salt treatment of crude glycerol - a novel approach for enhanced biohydrogen production from the biodiesel industry waste. Bioresource Technol. 151, 49-53.

Seo, Yh., Ig, Lee, Ji, Han, 2013. Cultivation and lipid production of yeast Cryptococcus curvatus using pretreated waste active sludge supernatant. Bioresource Technol. 135, 304-308.

Sidnei, G.S., Ángel, M.-R., Miguel, d.L.G., Fábio, R.P.R., 2011. Sequential spectrofluorimetric determination of free and total glycerol in biodiesel in a multicommuted flow system. Anal. Bioanal. Chem. 401, 365-371.

Swearingen T. 2006. Separating glycerine/FFAs. Avaiable at <http:// journeytoforever.org/biodiesel_glycsep.html> (accessed Dec. 2012).

Thiru, M., Sankh, S., Rangaswamy, V., 2011. Process for biodiesel production from Cryptococcus curvatus. Bioresour. Technol. 102, 10436-10440.

Trchounian, K., Poladyan, A., Trchounian, A., 2016. Optimizing strategy for Escherichia coli growth and hydrogen production during glycerol fermentation in batch culture: effects of some heavy metal ions and their mixtures. Appl. Energy 177, 335-340.

Uprety, B.K., Dalli, S.S., Rakshit, S.K., 2017. Bioconversion of crude glycerol to microbial lipid using a robust oleaginous yeast Rhodosporidium toruloides ATCC 10788 capable of growing in the presence of impurities. Energy Conver. Manage. 135, 117-128.

Verma, P., Sharma, M.P., Dwivedi, G., 2016. Evaluation and enhancement of cold flow properties of palm oil and its biodiesel. Energy Rep. 2, 8-13.

Vicente, G., Bautista, L.F., Rodríguez, R., Gutiérrez, F.J., Sádaba, I., Ruiz-Vázquez, R.M., Torres-Martínez, S., Garre, V., 2009. Biodiesel production from biomass of an oleaginous fungus. Biochem. Eng. J. 48, 22-27.

Wassner, D., Borrás, M., Vaca-Garcia, C., Ploschuk, E., 2016. Harvest date modifies seed quality and oil composition of Jatropha curcas growth under subtropical conditions in Argentina. Ind. Crops Prod. 94, 318-326.

Woyewoda P.J.K, A.D., Regier L.W, Ackman R.G. 1976. An improved titrametric method for determination of free fatty acid in fish oils. Environment Canada Fisheries and Marine Service Technology Branch Halifax- Nova Scotia New Series Circular No. 61, November 1976.

Xu, J., Zhao, X., Wang, W., Du, W., Liu, D., 2012. Microbial conversion of biodiesel byproduct glycerol to triacylglycerols by oleaginous yeast Rhodosporidium toruloides and the individual effect of some impurities on lipid production Biochem. Eng. J. 65, 30-36.

Yang, X., Jin, G., Wang, Y., Shen, H., Zhao, Z.K., 2015. Lipid production on free fatty acids by oleaginous yeasts under non-growth conditions. Bioresource Technol. 193, 557-562.

Yen, H.-W., Yang, Y.-C., Yu, Y.-H., 2012. Using crude glycerol and thin stillage for the production of microbial lipids through the cultivation of Rhodotorula glutinis. J. Biosci. Bioeng. 114, 453-456.

Zhang, X., Yan, S., Tyagi, R.D., Surampalli, R.Y., Valéro, J.R., 2016. Energy balance of biofuel production from biological conversion of crude glycerol. J. Environ. Manage. 170, 169-176.

Zhang, X., Chen, J., Yan, S., Dayal Tyagi, R., Surampalli, R.Y., Li, J., 2017. Lipid Production for Biodiesel from Sludge and Crude Glycerol. Water Environ. Res. 89, 424-439.

Zheng, Y., Chi, Z., Ahring, B.K., Chen, S., 2012. Oleaginous yeast Cryptococcus curvatus for biofuel production: ammonia's effect. Biomass Bioenergy 37, 114-121. 